\title{
TR02
}

\section{Significance of Clay Mineralogy for Reservoir} Quality Prediction

H. El Hajj* (Halliburton Energy Services Inc.), W. Suzart (Halliburton Energy Services Inc.), M. Al Tammar (Halliburton Energy Services Inc.), T. Al-Ghamdi (Halliburton Energy Services Inc.) \& A. Al-Abdullatif (Halliburton Energy Services Inc.)

\section{SUMMARY}

This paper provides insight into the importance of knowing the minerals present in the reservoir, particularly the total clay percentage. It is vital to know the types and percentages of clays present for effective reservoir treatment and analysis. During the evolution of a petroliferous sedimentary basin, the clay minerals contained in the rocks undergo a series of changes in composition and crystal structure in response to tectonics and sedimentation. The amount and type of clay minerals are a function of the provenance of clastic minerals and of diagenetic reactions at shallow and greater depth in different tectonic and sedimentary settings. Clay minerals can be used to infer tectonic/structural regime, basin evolution history, and the timing of various geologic events. 
This paper provides insight into the importance of knowing the minerals present in the reservoir, particularly the total clay percentage. It is vital to know the types and percentages of clays present for effective reservoir treatment and analysis. During the evolution of a petroliferous sedimentary basin, the clay minerals contained in the rocks undergo a series of changes in composition and crystal structure in response to tectonics and sedimentation. The amount and type of clay minerals are a function of the provenance of clastic minerals and of diagenetic reactions at shallow and greater depth in different tectonic and sedimentary settings. Clay minerals can be used to infer tectonic/structural regime, basin evolution history, and the timing of various geologic events.

The clay minerals, including kaolinite, smectite, illite, and chlorite, are ubiquitous in the targeted rocks of oil and gas exploration. Clay minerals were studied to predict the quality of organic rich source rock and the generation mechanism when scientists attempted to investigate the origin of oil and gas. The clay minerals analysis was then used as a tool in terms of environmental determination, stratigraphic correlation, and hydrocarbon generation zone identification to determine the exploration target interval. The minerals present in the reservoir, especially the clay minerals, can play the utmost role, which affects both the reservoir capacity and production. The grain size of clay minerals is generally very small and results in very low effective porosity and permeability; consequently, any presence of clay in a reservoir may have direct consequences on the reservoir properties.

Clays pose challenges in that they are well known for swelling in the presence of water. Within their crystalline layers, clays contain cations, typically sodium, that occupy base exchange positions or sites. Upon contact with water, these cations are solubilized, resulting in clay instability and often swelling. When clay swells, the ability of the clay-containing land to permit the passage of liquids, drilling or fracturing fluids, and hydrocarbons, is diminished, impeding production.

For the operator, knowing the clay mineralogy is necessary to determine the effectiveness of the current clay stabilization treatment. Knowing the reservoir clay type and abundance is needed to better understand the response for petrophysical analysis, as well. Diagenetic clays, such as smectite and illite, are of particular interest; they can have pronounced effects on production rates and damage through improper treatment because of the lack of understanding of the targeted formation lithology.

In addition, the presence of swelling clays is generally associated with drilling problems, such as stuck pipe. These problems can result in poor cement jobs and sensitivity to completion fluids. Poor hole quality in the producing interval can result in significant migration of fluids behind pipe, leading to reduced fluids control in the wellbore. These problems are encountered if either the producing formation or the intervening shales contain substantial quantities of swelling clays. When swelling clays are present in the producing interval, formation damage problems can occur because of rate sensitivity or water sensitivity. Care must be exercised to ensure that production rates and drawdowns in these wells are maintained so that the critical velocity is not exceeded in the near-wellbore region.

To prevent fines migration and clay swelling, various chemical treatments have been designed. These include polymers that contain quaternary ammonium salts and hydrolyzable metal ions, such as zirconium oxychloride, hydroxy-aluminum, and polymerizable ultrathin films.

Each of these methods relies on coating the fines (which are usually negatively charged) with large polyvalent cations that can attach irreversibly to the mineral surfaces. When the electrostatic charges on the fines are neutralized, the likelihood of fines migration is reduced significantly. Fines-stabilizing chemicals have been used in treatments, such as acidizing, gravel packing, and fracturing.

The clay stabilization process provides a permanent solution to water infectivity. The use of clay stabilizers reduces clay swelling; they function through ion exchange in which the clay stabilizer provides a cation to replace the native, solubilized clay cation, such as sodium. Potassium chloride $(\mathrm{KCl})$ is commonly used to reduce clay swelling in which the potassium ion is effective in preventing swelling. It also presents certain challenges. Potassium chloride is often used at high levels (2 to $4 \%$ ) and requires handling at the site to prepare a solution. In addition, potassium chloride can be incompatible with other materials, negatively affecting other aspects of fracturing fluids, such as 
gelation. Choline chloride $(75 \%)$ and choline bicarbonate $(75 \%)$ provide an attractive alternative. They serve as an effective temporary clay stabilizer $/ \mathrm{KCl}$ substitute for the smectite, illite, and mixed layer clay minerals commonly found in formations.

Therefore, to properly evaluate and explore clays, appropriate types of rock property data must be measured and cross checked with log data. These integrated data will provide operators with the critical parameters needed to help define the best brittle reservoir interval and avoid exploration failure by selecting the compatible drilling and hydraulic fluids. In addition, special blends can be identified for a more effective approach in dealing with abnormal mineralogy and complex shale.

Various analytical techniques are used to determine and characterize clay. The mineralogical compositions of clays is primarily determined by advanced X-ray powder diffraction analyses. These analyses include determinations of the bulk (whole rock) compositions of samples by full pattern fitting and by even more detailed determinations of the types of and relative abundance of clay minerals based on analyses of clay size fractions, usually $<2$ micron. In addition, chemical analyses, for example by X-ray fluorescence (XRF), provide complementary information about the chemical composition of clays. Various chemical and physical properties, such as cation exchange capacity (CEC), surface area and porosity, are also determined. Fundamentally, the reactivity of many samples is determined by how the clay minerals are stabilized by chemical treatment. Physical properties and analyses can help also to understand the behavior of clays in the subsurface. Desirable physical properties, such as brittleness, can also be related to mineralogical compositions. Other techniques, such as scanning electron microscopy (SEM), can also be used to view the micro-structure of clays. The maturity of clays (degree of diagenesis) is also a factor that influences brittleness and fracturability because crystal growth processes, particularly of clay minerals, result in the coarsening of particle size and changes in texture. A liner swell meter test can also be used to obtain the most accurate data possible regarding the swelling capacity in shale samples.

This paper summarizes the importance of clay characterization, various chemical techniques for clay swelling treatment and clay stabilization, and the importance of clay characterization in drilling operations. A case study will be presented. 